\title{
THE CONCENTRATIONS OF CYSTEINE AND CYSTINE IN HUMAN BLOOD PLASMA
}

\author{
By M. PRINCE BRIGHAM,* WILLIAM H. STEIN ANd STANFORD MOORE
}

(From The Rockefeller Institute, New York 21, N. Y.)

(Submitted for publication June 13, 1960; accepted July 8, 1960)

Studies on the amino acid content of physiological fluids have usually been carried out under conditions that would permit any cysteine present to be oxidized to cystine prior to analysis. Consequently, little quantitative information has been obtained concerning the relative amounts of the - $\mathrm{SH}$ and the $-\mathrm{S}-\mathrm{S}$ - forms of the amino acid in plasma. To know whether both forms are present is of particular importance in the study of excretion of amino acids by the kidney. Cystine is an amino acid which appears in abnormal quantities in the urine in several pathological conditions (1). Failure of tubular reabsorption has usually been invoked to explain this fact (2), an explanation which tacitly assumes that it is cystine (the - $\mathrm{S}-\mathrm{S}$ - form) not cysteine (the - $\mathrm{SH}$ form) that is circulating in the blood and is cleared by the kidney. If cysteine were to be the predominant form normally circulating, oxidation to cystine in the kidney would be required in order to account for the excretion of the disulfide in the urine.

Fujita and Numata (3) and Smith and Tuller (4) have reported the presence of cysteine in blood. Another observation which could bear on the subject is that of Brand, Cahill and Harris (5) who showed that the amount of cystine in the urine of a cystinuric subject rose after feeding cysteine and methionine, but not after the ingestion of cystine, the sulfur of which appeared almost exclusively as urinary sulfate.

With these thoughts in view, a method has been developed to determine cysteine and cystine individually in the same sample of plasma. The method is based upon the fact that iodoacetate reacts rapidly with cysteine to convert it quantitatively to the stable S-carboxymethyl derivative, which can be determined chromatographically $(6$, $7)$. In the system of elution described $(7,8)$ for

* United States Public Health Service Fellow; present address: Temple University School of Medicine, Philadelphia, $\mathrm{Pa}$. the analysis of physiological fluids with ion exchange columns, the compound emerges between urea and aspartic acid, in a position on the effluent curve not occupied by any other ninhydrinpositive substance normally found in blood plasma. Cystine is unaffected by iodoacetate and hence appears at its usual position, after valine. An effluent curve obtained by automatic recording equipment from a sample of plasma treated with iodoacetate is shown in Figure 1. In a small series of experiments, the same analytical procedure has also been found to be fairly satisfactory for the estimation of the amounts of cystine and cysteine in freshly voided urine.

\section{MATERIALS AND METHODS}

Subjccts. The normal subjects (I-IV) were white healthy males ranging from the early thirties to the late forties in age. Subject V was a 19 year old Negro male who had been hospitalized for a minor stab wound of the chest about 4 days previously. The cystinuric subject (W.E.) was healthy but had suffered periodically from cystine stones which had been removed surgically on several occasions. The two subjects with Fanconi syndrome (cystine storage disease) were brothers aged 4 years (D.M.; weight 36 pounds) and 7 years (S.M.; weight 47 pounds). They presented all the findings typical of the disease [cf. Bickel, Smallwood, Smellie and Hickmans (9) ], including small stature, bone changes due to rickets, cystine storage manifested by cystine crystals in the cornea, and amino aciduria. They also showed kidney damage. The younger had a blood urea nitrogen of $32 \mathrm{mg}$ per $100 \mathrm{ml}$ and a maximal urea clearance of 33.7 to 34.9. The corresponding values for the older brother were $79 \mathrm{mg}$ per $100 \mathrm{ml}$ and 7.7 to 8.7 .

Samples. Somewhat more than $10 \mathrm{ml}$ of blood from the antecubital vein was drawn into a dry syringe through a no. 19 gage needle. All subjects had fasted overnight. The blood was immediately ejected through the needle into a $10 \mathrm{ml}$ volumetric flask that contained $100 \mathrm{mg}$ of iodoacetic acid (Matheson, Coleman and Bell, East Rutherford, N. J.), $42 \mathrm{mg}$ of $\mathrm{NaHCO}_{3}$, and $20 \mathrm{mg}$ of disodium ethylenediaminetetraacetate (EDTA), all dissolved in $1 \mathrm{ml}$ of $0.1 \mathrm{M}$ phosphate buffer at $\mathrm{pH} 6.8$. The flask was filled to the mark with blood, and the remainder was placed in a heparinized tube for the determination 


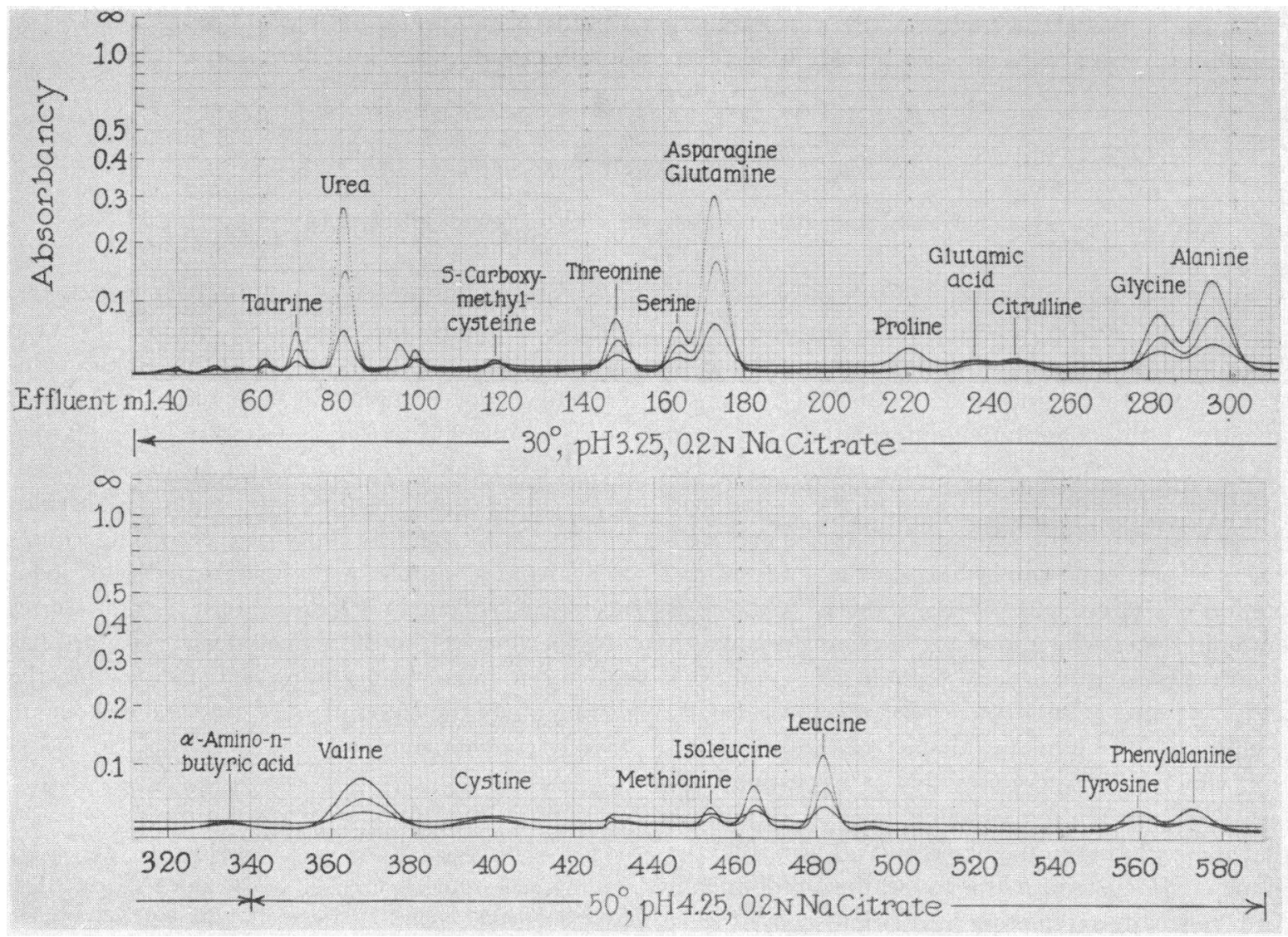

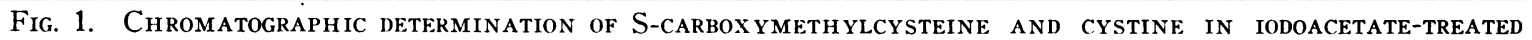
NORMAL BLOOD PLASMa. The sample on the ion exchange column corresponded to $1.4 \mathrm{ml}$ of normal fasting plasma. The effluent was analyzed with automatic recording equipment (7) for the acidic and neutral amino acids. The results of the analysis are tabulated in Table I (Subject I).

of the hematocrit. If a larger or a smaller amount of blood was used, the amounts of all of the other constituents were adjusted proportionately. The plasma was separated by centrifugation (during which time the reaction of cysteine and iodoacetate proceeds to completion), deproteinized with picric acid, and freed of picric acid by the use of a bed of Dowex 1-X8, as described previously (10), except that the step wherein cysteine was oxidized to cystine was not required. The sample was concentrated almost to dryness on a rotary evaporator and washed into a $5 \mathrm{ml}$ volumetric flask with buffer at pH 2.2 (7). The aliquot taken for each chromatographic analysis was $2 \mathrm{ml} .{ }^{1}$ Protein-free specimens were stored, if necessary, at $-20^{\circ} \mathrm{C}$ prior to analysis.

1 The peaks from both S-carboxymethylcysteine and cystine are relatively small, and the steady baseline obtained with the automatic recording equipment facilitates the analysis. It would be more difficult to determine the two compounds by the manual method (8), and with either procedure the accuracy would be increased by using a larger load more closely equivalent to $4 \mathrm{ml}$ of blood plasma (11).
For the analysis of urine, an aliquot of a freshly voided sample obtained from a fasting subject was added to a $10 \mathrm{ml}$ volumetric flask containing the reagents given above for the treatment of blood. After 20 minutes, to allow the reaction of iodoacetate with cysteine to proceed to completion, an aliquot was removed and brought to $\mathrm{pH} 2.2$ by the addition of $\mathrm{N} \mathrm{HCl}(0.1$ to $0.2 \mathrm{ml}$ per $\mathrm{ml}$ of urine). The volume of sample chromatographed was determined on the basis of the specific gravity of the undiluted urine sample; an amount was used that corresponded to about $2 \mathrm{ml}$ of urine of specific gravity 1.020 (e.g., $4 \mathrm{ml}$ of urine, sp gr 1.010). Urine samples may be stored frozen under toluene after reaction with iodoacetate, although there is a loss of methionine with time.

Chromatographic analyses. All analyses were performed with the aid of the automatic recording equipment described by Spackman, Stein and Moore (7). The $30^{\circ}$ to $50^{\circ}$ system recommended for the analysis of physiological fluids (8) was employed [cf. Moore, Spackman and Stein (11) ]. Under these conditions, S-carboxymethylcysteine emerges at about $120 \mathrm{ml}$, or $32 \mathrm{ml}$ before threonine. The S-carboxymethyl derivative of reduced 
glutathione, not normally observed, emerges at about $52 \mathrm{ml}$ before threonine.

In calculating the amino acid content of the plasma, allowance must be made for the dilution brought about by the reagent solution present in the volumetric flask into which the freshly drawn blood is introduced. For example, if $9 \mathrm{ml}$ of whole blood is added to $1 \mathrm{ml}$ of reagent solution ( $10 \mathrm{ml}$ volumetric flask), and if the hematocrit is 45 per cent (including the buffy coat), there would be 55 per cent of plasma, or $9 \times 0.55=4.95 \mathrm{ml}$ of the plasma before dilution. The total volume of diluted plasma is then $5.95 \mathrm{ml}$, and if $5.0 \mathrm{ml}$ of diluted plasma is pipetted off after centrifugation of the cells, this volume would be the equivalent of $(4.95 / 5.95) \times 5.0=4.16 \mathrm{ml}$ of true plasma. The subsequent calculations are the same as those for the usual analysis of blood plasma (10). (The above calculation neglects the small volume correction for the solid reagents added initially.)

\section{RESULTS}

The cystine and cysteine content of plasma. A typical elution curve obtained from an iodoacetatetreated, deproteinized sample of human blood plasma is shown in Figure 1. Qualitatively, the only significant difference between this curve and one obtained from plasma not treated with iodo- acetate [(11), Figure 4] is the appearance of the peak at $120 \mathrm{ml}$ which is attributable to S-carboxymethylcysteine. (There also appears a small peak with maximal absorption at $440 \mathrm{~m} \mu$ just after urea.) A cystine peak is still present, so it is clear that plasma contains both cystine and cysteine. Although iodoacetate is known to react with other functional groups of amino acids $(12,13)$, the alkylation of sulfhydryl groups at neutrality is by far the most rapid reaction, being complete in less than 20 minutes at $\mathrm{pH} 6$ and room temperature.

The observed cystine and cysteine contents of several samples of plasma are given in the top section of Table I. The amount of the $-\mathrm{S}-\mathrm{S}-$ form is between 2 and 5 times that of the $-\mathrm{SH}$ form. Concentrations of the other amino acids are listed in the lower part of the table; determinations of the basic amino acids were not carried out in every instance. The figures given for the neutral and acidic amino acids nearly all fall within the range of normal values determined previously (10), and the figures for cystine and cysteine thus appear to be representative for normal plasma.

TABLE I

Free amino acids of human blood plasma*

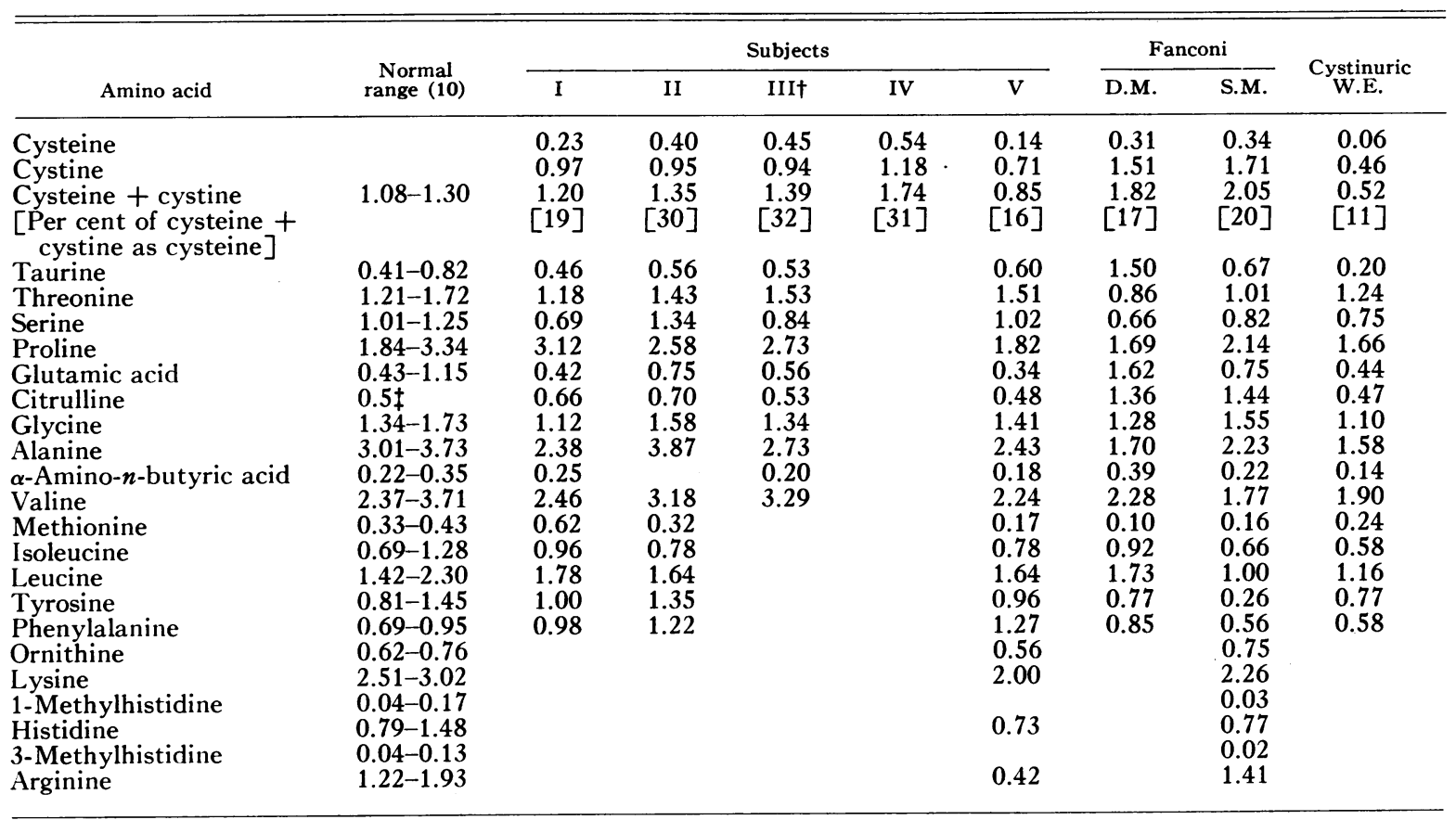

* Subjects were all in the postabsorptive state. All values are expressed in milligrams per $100 \mathrm{ml}$ of venous plasma. $\dagger$ Last portion of determination was lost.

$\ddagger$ Value from Archibald (14). 
TABLE II

The cystine and cysteine content of urine *

\begin{tabular}{|c|c|c|c|c|c|c|}
\hline \multirow[b]{2}{*}{ Amino acid } & \multicolumn{3}{|c|}{ Normal } & \multicolumn{2}{|c|}{ Fanconit } & \multirow{2}{*}{$\begin{array}{l}\text { Cystinuric } \\
\text { W.E. }\end{array}$} \\
\hline & I & III & $\mathrm{VI}$ & D.M.. & S.M. 8 & \\
\hline $\begin{array}{l}\text { Cysteine } \\
\text { Cystine } \\
\text { Cysteine [as per cent } \\
\text { of cystine + cysteine] }\end{array}$ & $\begin{array}{c}4 \\
8 \\
{[33]}\end{array}$ & $\begin{array}{c}4 \\
14 \\
{[22]}\end{array}$ & $\begin{array}{c}3 \\
15 \\
{[17]}\end{array}$ & $\begin{array}{c}4 \\
15 \\
{[21]}\end{array}$ & $\begin{array}{c}4 \\
35 \\
{[11]}\end{array}$ & $\begin{array}{c}1 \\
756 \\
{[0.1]}\end{array}$ \\
\hline
\end{tabular}

* Values are expressed as milligrams per liter of fasting urine.

† The average daily urine excretion for both subjects was about $2,000 \mathrm{ml}$.

The values expressed as milligrams per gram of creatinine are 39 for cysteine and 133 for cystine.

$\S$ The values expressed as milligrams per gram of creatinine are 17 for cysteine and 131 for cystine.

In both of the children suffering from the Fanconi syndrome, the cystine in the plasma is slightly elevated, but the cysteine is in the normal range. In the cystinuric subject, both cysteine and cystine are low.

The adequacy of the iodoacetate procedure was checked by recovery experiments in which a known quantity $(0.1 \mathrm{ml}$ of a 1 per cent solution $)$ of cysteine $\cdot \mathrm{HCl}$ was added to one-half of a sample of whole blood prior to the iodoacetate treatment. Thereafter both halves were carried through the iodoacetate procedure and the chromatographic analyses in tandem. The recovery of added cysteine in two such experiments was 96 per cent and 98 per cent. $^{2}$

The amount of iodoacetic acid added in the present experiments is a 50 -fold excess, calculated on the basis of the total sulfhydryl content of serum (predominantly - $\mathrm{SH}$ of serum proteins) reported by Goldblum, Piper and Olsen (15). The results of the recovery experiments indicate that this amount of reagent is sufficient to cause complete alkylation of all of the cysteine likely to be found in plasma. Oxidation of some cysteine to cystine during the period of the reaction with iodoacetate is effectively prevented by the presence of EDTA. The chelating agent not only serves as an anti-

2 The purity of the added cysteine $\cdot \mathrm{HCl}$ (of known $\mathrm{C}$, $\mathrm{H}$, and $\mathrm{N}$ content) was checked by treating a portion of it with excess iodoacetate prior to chromatographic analysis. The cysteine $\cdot \mathrm{HCl}$ was dissolved in $0.1 \mathrm{M}$ phosphate buffer at $\mathrm{pH} 6.8$ containing 0.2 per cent EDTA to stabilize the solution. Upon chromatography of an aliquot of the reaction mixture on a $15 \mathrm{~cm}$ column of Am-

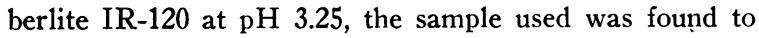
contain 93 per cent cysteine (recoverable as carboxymethylcysteine) and 7 per cent cystine. These values were used in calculating the recoveries from blood. coagulant, but also protects sulfhydryl groups from the oxidation normally catalyzed by traces of metal ions. Without EDTA, cysteine in $0.003 \mathrm{M}$ solution at $\mathrm{pH} 6.8$ will be oxidized to the extent of 30 per cent in 45 minutes, as determined by the spectrophotometric method of Alexander (16). In the presence of the chelating agent, on the other hand, there is no decrease in sulfhydryl content during the first 60 minutes.

The cystine and cysteine content of urine. The determination of cysteine in urine as the S-carboxymethyl derivative is less precise than it is in blood. The effluent curve from urine not treated with iodoacetate (which needs to be obtained as a control) exhibits a peak very close to and partially overlapping the small carboxymethylcysteine peak, which renders the integration of the latter less certain. The recovery of cysteine added to urine was high, 113 per cent, which reflects the possible error in the integration. The conclusion that the new peak, which appears at the carboxymethylcysteine position when freshly voided urine is treated with iodoacetate, arises from cysteine is well supported by the finding that, when urine has first been allowed to stand under toluene for 24 hours at $4^{\circ} \mathrm{C}$ which would convert cysteine to cystine, no new peak at the carboxymethylcysteine position appears after treatment with iodoacetate.

The results of analyses for cystine and cysteine in several urine samples are given in Table II. Normal urine clearly contains both cystine and cysteine, and in about the same ratio as normal blood. The total cystine plus cysteine content is in the range previously given $(17,18)$ for cystine alone; the earlier values were obtained under con- 
ditions which would have allowed cysteine to be oxidized to cystine prior to analysis.

The results obtained from the Fanconi patients are somewhat difficult to evaluate. The concentrations of cystine and cysteine are not markedly increased, but the amount excreted per day is abnormally large as a result of the elevation in urine volume. The ratio of cystine to creatinine is also much higher than normal. Both of the subjects excreted about $130 \mathrm{mg}$ of cystine per $\mathrm{g}$ of creatinine, whereas the normal values for an infant lie between 28 and $54 \mathrm{mg}$, and those for a child, between 10 and $14 \mathrm{mg}$ (19). Determination of the other amino acids in the urine showed these subjects to have a marked but not a massive aminoaciduria when the results are compared with those for a normal child of about the same age (20). The amino acid output was more nearly comparable with that observed for infants (19), particularly as proline and hydroxyproline were found. These two amino acids are characteristic constituents of infants' urine, but not of the urine of children and adults. The values for serine, threonine, citrulline, and lysine were particularly high.

The high cystine excretion of the cystinuric is typical for an individual suffering from this condition. The cysteine content of the urine is slightly below the normal range.

\section{DISCUSSION}

The data presented in this communication show that both cysteine and cystine are normally found in blood and urine, and that the disulfide predominates. Clearance calculations (2) for cystine in normal individuals will require reconsideration, but the changes in the numerical values will be small since the ratio of the two forms in urine is found to be similar to that in the blood. Cystinuria is clearly associated with a high rate of clearance of cystine (2); there is as yet no evidence that blood cysteine is the precursor of cystine in the urine in this abnormality, even though Brand, Cahill and Harris (5) have shown that ingestion of cysteine (but not cystine) led to increased excretion of cystine in the urine. It is apparent that the metabolic relationships between the $-\mathrm{SH}$ and - S- S- forms of the amino acid are not fully understood. Methods such as the present one may permit further studies of the relationships of the two forms in different tissues as well as additional investigations of their excretion by the kidney in normal and pathological conditions.

\section{SUMMARY}

1. A method has been developed for the determination of cystine and cysteine in the same sample of fresh blood or urine. Cysteine is determined by converting it immediately to the stable S-carboxymethyl derivative by reaction with iodoacetate. The other amino acids are not affected. The amino acid composition, including the S-carboxymethylcysteine content, is determined by ion exchange chromatography on columns of sulfonated polystyrene resins.

2. Normal human plasma obtained from individuals in the postabsorptive state contains about $1 \mathrm{mg}$ of cystine and $0.4 \mathrm{mg}$ of cysteine per $100 \mathrm{ml}$. The values for a single cystinuric subject were both slightly low, whereas the cystine (but not the cysteine) content of the plasma of two subjects suffering from the Fanconi syndrome was somewhat high.

3. The normal individual excretes, in the fasting state, 10 to $15 \mathrm{mg}$ of cystine and 2 to $4 \mathrm{mg}$ of cysteine per $L$ of urine. The two Fanconi subjects, both of whom exhibited aminoaciduria, had an elevated cystine excretion, but the cysteine content of the urine was essentially normal. In a cystinuric, the cystine excretion was massive, but the cysteine concentration was slightly subnormal.

\section{ACKNOWLEDGMENT}

The authors are greatly indebted to Dr. Reginald M. Archibald of the Hospital of the Rockefeller Institute. His generous cooperation made possible the studies of the patients with Fanconi syndrome. We also wish to acknowledge the expert assistance of Miss Ann Benson and Miss Anna Zamoyska in the performance of the chromatographic analyses.

\section{REFERENCES}

1. Dent, C. E., and Walshe, J. M. Amino-acid metabolism. Brit. med. Bull. 1954, 10, 247.

2. Arrow, V. K., and Westall, R. G. Amino acid clearances in cystinuria. J. Physiol. 1958, 142, 141.

3. Fujita, A., and Numata, I. Über die kolorimetrische Bestimmung von Cystein und Cystin. Biochem. Z. 1938-39, 300, 264.

4. Smith, E. L., and Tuller, E. F. The paper chromatographic detection of the free-sulfur containing 
amino acids and small peptides in whole blood and serum. Arch. Biochem. 1955, 54, 114.

5. Brand, E., Cahill, G. F., and Harris, M. M. Cystinuria II. The metabolism of cystine, cysteine, methionine, and glutathione. J. biol. Chem. 1935, 109, 69.

6. Moore, S., Cole, R. D., Gundlach, H. G., and Stein, W. H. On the cleavage of disulfide bonds by reduction in Proceedings of IVth Internat. Congr. of Biochemistry, Vienna, 1958; Symposium. VIII, Proteins. New York, Pergamon Press, 1958, p. 52.

7. Spackman, D. H., Stein, W. H., and Moore, S. Automatic recording apparatus for use in the chromatography of amino acids. Analyt. Chem. 1958, 30, 1190 .

8. Moore, S., Spackman, D. H., and Stein, W. H. Chromatography of amino acids on sulfonated polystyrene resins. An improved system. Analyt. Chem. 1958, 30, 1185.

9. Bickel, H., Smallwood, W. C., Smellie, J. M., and Hickmans, E. M. Clinical description, factual analysis, prognosis and treatment of Lignac-Fanconi disease. Acta paediat. Uppsala 1952, 42, Suppl. 90, p. 27.

10. Stein, W. H., and Moore, S. Free amino acids of human blood plasma. J. biol. Chem. 1954, 211, 915.

11. Moore, S., Spackman, D. H., and Stein, W. H. Automatic recording apparatus for use in the chromatography of amino acids. Fed. Proc. 1958, 17, 1107.

12. Korman, S., and Clarke, H. T. Carboxymethylamino acids and peptides. J. biol. Chem. 1956, 221, 113.

13. Gundlach, H. G., Stein, W. H., and Moore, S. The nature of the amino acid residues involved in the inactivation of ribonuclease by iodoacetate. J. biol. Chem. 1959, 234, 1754.

14. Archibald, R. M. Determination of citrulline and allantoin and demonstration of citrulline in blood plasma. J. biol. Chem. 1944, 156, 121.

15. Goldblum, R. W., Piper, W. N., and Olsen, C. J. Studies on sulfhydryl groups in sera of normal humans. J. invest. Derm. 1954, 22, 373.

16. Alexander, N. M. Spectrophotometric assay for sulfhydryl groups using N-ethylmaleimide. Analyt. Chem. 1958, 30, 1292.

17. Stein, W. H. Chromatographic investigation of the amino acid constituents of normal urine. J. biol. Chem. 1953, 201, 45.

18. Evered, D. F. Excretion of amino acids by the human; a quantitative study with ion-exchange chromatography. Biochem. J. 1956, 62, 416.

19. Fowler, D. I., Norton, P. M., Cheung, M. W., and Pratt, E. L. Observations on the urinary amino acid excretion in man: The influence of age and diet. Arch. Biochem. 1957, 68, 452.

20. Jonxis, J. H. P., and Huisman, T. H. J. Amino aciduria and ascorbic acid deficiency. Pediatrics 1954, 14, 238. 